\title{
UZBEKISTAN-SOUTH KOREA: NEW PERSPECTIVES OF COOPERATION IN THE EDUCATION SECTOR
}

\author{
M.T.Alokhanov \\ Ph.D. student at Tashkent State Pedagogical, \\ University named after Nizami
}

Article DOI: https://doi.org/10.36713/epra2307

\section{RESUME}

This article highlights the stages of development of the international cooperation of the Republic of Uzbekistan with South Korea in the education sector, the country where cooperation is established, the results of cooperation, and plans. Furthermore, it analyses the reforms carried out in the field of education during the independence in Uzbekistan.

KEYWORDS: education, reform, civilization, subject, country, culture, scientist, academy, coexistence, law, government, benefit

\section{THE TOPICALITY OF THE PROBLEM}

One of the main purposes of the foreign policy of the Republic of Uzbekistan is to develop cooperation with developed countries [1]. Therefore, Uzbekistan has established cooperation with a lot of countries all over the world and has been developing this cooperation. Based on this idea we can say that the establishment of cooperation with countries that are economically developed in Asia is significantly beneficial to Uzbekistan. Because it is beneficial for countries in Asia to establish cooperation with the Republic of Uzbekistan, which has its location and geopolitical status in Central Asia, rich natural resources, population, and its high scientific potential. Simultaneously, it is also significantly important to Uzbekistan to cooperate and develop it with Asian countries that have their political influence on the continent of Asia, the most influential in the Asian region, considered the most developed countries in the world in terms of economic growth and have high technologies, and have a wide range of opportunities to use their achievements and experience. After gaining its independence and choosing its free development path, Uzbekistan began to take part actively in international relations as an equal member of the world community. Uzbekistan has begun to join confidently the world community relying on such principles equality in mutual relations, noninterference in the internal affairs of other states, development of mutually beneficial and equal cooperation, ensuring peace, security, and stability in the region and the world.

The integrating of the Republic of Uzbekistan into the world community and taking a worthy place in the system of international relations is determined by the effective implementation of its interests in the political, economic, scientific, technical, and social spheres. After gaining independence, Uzbekistan has begun the process of strengthening and modernizing the education system under the influence of national life and pedagogical thought, as well as advanced experience in the world. An opportunity to compare the achieved results with other countries, to learn the positive aspects of them, and to share and enrich the results and goals of Uzbekistan in this sphere with others appeared. Over the past thirty years, cooperation in the education field has developed extensively. In particular, cooperation with South Korea in the education sector is becoming increasingly significant and plays a pivotal role in the development of the education system of Uzbekistan.

\section{METHODOLOGY}

In investigating the subject, we based on the principles of historical, objectivity, comparative comparison, chronological sequence, and historical consistency.

\section{LITERATURE REVIEW}

It should be noted that the result of systematic analysis of existing scientific resources showed that it is not sufficiently covered the issues of cooperation of the Republic of Uzbekistan in the field of 
education and science with developed countries of the world, such as South Korea. However, this does not mean that the issues of cooperation between the two countries in the field of education in Uzbekistan have not been studied at all. In particular, a lot of scientific publications, articles, and dissertations have been written in this regard. V. Han (History of Korea. 2013), Sun Don Gi (Relations between the Republic of Uzbekistan and South Korea: the establishment of economic and cultural relations.2000) are among them.

\section{RESULTS}

Education is an important component of the social life of the society. The level of development of a particular country and the socio-economic condition of a society largely depends on how it develops. Realizing this objective fact the Uzbek government takes all necessary measures for the comprehensive development of the scientific potential of the Republic of Uzbekistan. These ongoing measures can be literally divided into the following two parts. They are measures being implemented in the territory of the Republic of Uzbekistan and with foreign countries based on international cooperation.

Thinking about the main tasks of the state in the field of education, President Shavkat Mirziyoyev said, "It is necessary to further improve the system of science, modern and life-long education. There is an aphorism among our people: "Education and upbringing begin in the cradle." Only enlightenment leads a person to perfection and society to progress. Therefore, the state policy in the field of education should be based on the principle of a system of lifelong education, that is, education should start from kindergarten and last a whole life" [2].

Uzbekistan gained its independence and determined as one of the great goals to cooperate in economic, scientific, technical, and cultural relations with foreign countries in order to enter the international arena. A lot of work has been done towards this goal. During the independence, the Republic of Uzbekistan has managed to establish and develop effective cooperation in science with many countries around the world. These countries include several countries in Asia. They are Japan, South Korea, China, Singapore, Malaysia, India, and several other developed countries. The education system in the countries mentioned above is also significant in that it has reached the development stage. Having reached such a stage of development, the Republic of Korea is one of the most developed countries in Asia, now having one of the top positions in the world. International cooperation of Uzbekistan with the Republic of Korea is one of the important factors in the rapid development of the educational and scientific potential of the country. In the history of our modern statehood, diplomatic relations were established between the Republic of
Korea and the Republic of Uzbekistan on January 29, 1992. Over the past 27 years, mutually beneficial cooperation based on respect and trust has developed and strengthened. Historical relations, strong friendship, strategic partnership, and mutually beneficial cooperation bind Uzbekistan and the Republic of Korea. This country actively participates in the implementation of large-scale programs in the process of reforms in the economic, political, and cultural spheres implemented in our country as one of the main foreign partners of Uzbekistan.

Uzbekistan and the Republic of Korea are separated by a long distance. Nevertheless, strong relations of friendship, historical and spiritual closeness of our peoples, bind Uzbekistan and Korea. This cooperation has deep roots. The Korean people gladly remember the kindness of Uzbek people shown to the Koreans who came to Uzbekistan during the Second World War due to fate. Tolerance, generosity, harmony, kindness, diligence are the common qualities of the Uzbek and Korean peoples. Spiritual closeness is the basis of mutual trust and respect. It should be pointed out that the warm attitude of the two peoples to each other has a positive impact on cooperation between the two countries. From the earliest days of cooperation to the present day, relations have been developing steadily. This can be seen from the opinions expressed by the heads of states. The following viewpoints of the President of the Republic of Uzbekistan Shavkat Mirziyoyev are a clear example of this point of view. "The Republic of Korea and the Republic of Uzbekistan are strategic partners. South Korea has gained a reputation in the world as a highly developed state with great economic, scientific-technical, innovative, and intellectual potential. We favorably appreciate our cooperation which is established based on openness, mutual understanding, and respect for interests" [3].

After gaining the independence of Uzbekistan, the relations between the Republic of Korea and the Republic of Uzbekistan took a new view.

Cooperation in the sphere of education is also significant in this regard. Science is a universal and international phenomenon according to its essence and nature. As the great scientist Frederic Julio Curie noted, "Science is a key element in uniting the minds of people scattered all over the globe and this is its highest virtue. In my opinion, there is no other field of human activity that people can reach a deal and agreement as quickly as in science" [4].

After the independence of Uzbekistan, the situation in the cultural and spiritual life of the country changed dramatically. "We all need to understand that," said the first President of the Republic of Uzbekistan Islam Karimov in this regard, - the situation in other spheres of our life, the effectiveness of the reforms carried out, first of all, the restoration of the spirituality of the people, the extensive study of our rich historical heritage, the 
preservation of our traditions are inextricably linked with the tradition of culture and art, science and education [5].

The ideas above have become a guideline for the development of education. The directions, procedure, rules, and level of cultural, scientific and technical relations between South Korea and Uzbekistan found its reflection in the documents adopted at the official meetings of the leaders of both states (July 16, 1992, June 4, 1994, January 16, 1995 , and October 4-6, 1999).

Particularly, the Declaration adopted during the official visit of the first president of the Republic of Uzbekistan Islam Karimov to South Korea in July 1992 put forward the issue of expanding mutual relations in the sphere of culture, art, education, and literature [6]. In the "Declaration of South Korea and Uzbekistan" adopted during the official visit of the President of South Korea to the Republic of Uzbekistan in June 1994, both states agreed on the issues of mutual exchange in the sphere of culture, art, education, science and technology, communication, sports, jointly publishing textbooks, encyclopedic dictionaries about the nations. A lot of work is being carried out based on these signed documents.

It is worth noting that in the Republic of Korea great attention is paid to the National Training Program which is implementing in Uzbekistan. In order to support the ongoing reforms of the Republic of Uzbekistan in this regard, the Eximbank of South Korea has allocated a preferential loan of 35 million US dollars to provide newly established academic lyceums, secondary schools with modern educational equipment in Uzbekistan [7]. Based on these agreements of the heads of states, a solid foundation has been laid for cultural, scientific, and technical relations between the two countries. The loan was used for important purposes.

Another important aspect of cooperation between the two countries in the field of education and culture is the ongoing cooperation in the field of higher education. Cooperation between higher education institutions is now one of the significant relations. As a prelude to this collaboration, it is possible to show as examples establishment of Korean language at the Tashkent State Pedagogical University named after Nizami and the Institute of Oriental Studies under the Ministry of Higher and secondary special education of the Republic of Uzbekistan. Initially, the Korean language was taught in the above two universities, and now the Korean language is being taught at several universities. To be precise, Korean philology is currently taught in 12 higher education institutions, 48 schools, and lyceums in the Republic of Uzbekistan [8]. The Uzbek State University of World Languages and the Samarkand State Institute of Foreign Languages are clear examples of our opinion. The higher educational institutions of our country have been cooperating with more than thirty scientific research institutions of the Republic of Korea. It should be noted that since 1992, the Korean educational center has been operating in Uzbekistan under the Embassy of the Republic of Korea, and more than 1,000 people study the Korean language every year in this center [9].

As well, the Uzbek language is taught in two institutes in South Korea. A special course on Uzbekistan is taught at the Bussan Institute of foreign languages and the Ho-Se Institute. In particular, the Uzbek language is taught in the Central Asian department of the Bussan Institute of foreign languages since 1995. A special Uzbek language department has been established at the Xo-Se Institute. However, these institutes lack specialists who are highly qualified and know Uzbekistan well. The government of Uzbekistan is providing significant assistance in this area [10].

The Republic of Korea is one of the leading countries in the world in the field of information and communication technologies. In the Republic of Uzbekistan, special attention is paid to the development of this sector. Consistent work is being carried out based on the comprehensive program for the development of the National Information and Communication System of the Republic of Uzbekistan for 2013-2020 and modern information technologies are widely introduced in all spheres.

The Ministry of Information Technologies and Communications of the Republic of Uzbekistan and the Ministry of Science, Information and Communication Technologies and Future Planning of the Republic of Korea have established effective cooperation. Specialists from South Korea contribute to the development of the electronic government system in our country and the training and professional development of personnel.

The establishment of a branch of Inkha University in Tashkent is a bright manifestation of the scope and prospects of cooperation in this field. At this University, students study at the level of international standards in the field of software development, management of information systems, and computer networks. The e-government training center and the Uzbek-South Korean information technology center are operating at the Tashkent University of information technology.

In addition, the Institute of history of the Academy of Sciences of the Republic of Uzbekistan carries out extensive work in the field of historical science. On the initiative of the Institute of history of the Academy of Sciences of the Republic of Uzbekistan in 2002, with the participation of South Korean historians, an international scientific conference was held in Tashkent on the topic Central Asia in the mirror of history: from the past to the future, and in 2003 Central Asia: ways of civilized development. The staff of the institute pays great 
attention to the development of cooperation with South Korean colleagues.

On July 6-7, 2011, the Tashkent State Institute of Oriental Studies hosted the 11th International Conference on Korean Studies "Uzbekistan-Korea: the states and prospects of historical, cultural and economic relations" dedicated to the 20th anniversary of independence of the Republic of Uzbekistan. The main purpose of the conference was to ensure an international exchange of experience and viewpoints of specialists on the issues related to the current problems of Korean Studies and achievements, based on this to create an opportunity for professionals of the field to develop future joint plans to address existing problems; Analysis of the dynamics of historical, cultural, economic and scientific relations between Uzbekistan and Korea; to improve the skills of young scientists. Such conferences are increasing year by year.

The agreements reached at the end of the historic high-level visit of the President of the Republic of Uzbekistan Shavkat Mirziyoyev to South Korea in November 2017 allowed raising to a new level of the mutually beneficial cooperation between our countries from the qualitative point of view and enriching it with concrete practical content. As a result of the meetings of the leaders of the two countries, significant changes have been observed in the field of education, as well as in other spheres. For example, branches of prestigious higher education institutions of the Republic of Korea begin operating in the Republic of Uzbekistan, and agreements on the opening of some of them have been implemented (Puchon university).

As well as, a number of works are also being carried out on vocational training based on Korean government grants. In particular, the adoption of the Resolution of the Cabinet of Ministers No. 135 of March 14, 2017 "On measures to establish a vocational training center in Shahrisabz city involving a grant of the government of the Republic of Korea" [9] is a vivid example of this positive work. It should also be noted that the above information is the beginning of a large-scale work in the field of education and science between the two countries. Cooperation between Uzbekistan and South Korea has been going on for many years and continues to be the same for both countries. There are plans to implement more projects in the framework of relations between the two countries, which will undoubtedly be beneficial for the two countries in the near future.

\section{CONCLUSION}

In conclusion, we can say that the Republic of Korea is one of the most reliable partners of Uzbekistan. At present, relations between two countries not only in the field of education but also in many areas are developing rapidly. Analysis of the achievements and results of the Republic of Korea in the field of education, exchange of views, and cooperation in the field of modern personnel are significantly important for Uzbekistan to take its place in the world community in every sphere. Because the role of education in the achievement of the current position of the Republic of Korea is significant.

\section{REFERENCES}

1. Kasymova. A., Guraev S. A. Topical issues of modern international relations. - Tashkent: Academy, 2008. - P. 233.

2. Mirziyoyev Sh. (2018). Address by the President of Republic of Uzbekistan Shavkat Mirziyoev to the Oliy Majlis on the most important priorities for 2019. December 28, 2018.

3. Matnazar Elmuradov, The President of the Republic of Korea has arrived in Uzbekistan. //The Newspaper “Xalq so'zi”, 2019. - № 79, p.1

4. Kyrgyzboyev A.K. International cooperation of the Republic of Uzbekistan with Asian countries. - Doctor of Historical Science, Dissertation. Tashkent, 2004, p. 231-232.

5. Karimom I.A. Uzbekistan aspires to the XXI century // We build our future with our own hands. Volume 7. - Tashkent: Uzbekistan, 1999. - p.78.

6. Sun Don Ki. Cooperation between the Republic of Uzbekistan and South Korea: the establishment and prospects of economic and cultural relations. Candidate of Historical Sciences, Dissirtation. - Tashkent, 2000. p.103104-107.

7. In the new century - partners // The newspaper Narodnoe slovoyu 1999. October 8.

8. http://uza.uz/oz/politics/presidents-toshkent-sharida-koreys-madaniyat-va-sanat-uyi-20-042019? sphrase_id $=1428506$.

9. Xan V.S. History of Korea. - Tashkent: Bakrtia press, 2013, p. 95

10. www.lex.uz 